\title{
LA EDAD DE \\ LOS «NUEVOS DERECHOS»
}

\author{
MARTA CARTABIA
}


SUMARIO

1. INTRODUCCIÓN: LOS DERECHOS TOTALES Y SU CRÍTICA 2. EL SUJETO DE DERECHOS. EL «YO»Y EL «NOSOTROS» 3. ¿QUIÉN ES EL SUJETO DE LOS NUEVOS DERECHOS? CASOS DE PRIVACIDAD EN EL DERECHO NORTEAMERICANO. 4. ¿QUIÉN ES EL SUJETO DE LOS NUEVOS DERECHOS? CASOS DE PRIVACIDAD EN EL DERECHO EUROPEO. 5. DE UN SUJETO EMPOBRECIDO A UNA ATROFIA DE LA RESPONSABILIDAD. 6. ¿QUIÉNES SON LOS NIÑOS DE LOS NUEVOS DERECHOS? 7. EN LA ENCRUCIJADA ENTRE LA JUSTICIA Y EL PODER: EN FAVOR DE UNA APROXIMACIÓN REALISTA A LOS DERECHOS HUMANOS. 


\title{
LA EDAD DE LOS «NUEVOS DERECHOS»*
}

POR

\author{
MARTA CARTABIA \\ Universidad de Milano-Bicocca \\ marta.cartabia@unimib.it
}

\section{INTRODUCCIÓN: LOS DERECHOS TOTALES Y SU CRÍTICA}

Los Derechos Humanos se encuentran ante una doble coyuntura. Al finalizar la Segunda Guerra Mundial, había expectativas de que un nuevo mundo ${ }^{1}$ tomara forma a partir de las bases compartidas de la Declaración Universal de los Derechos Humanos. Una vez transcurrido más de medio siglo desde entonces, sin embargo, los derechos más elementales todavía son negados en conjunto a personas sin capacidad de hacerlos valer en muchas zonas del mundo. En muchos países, hasta los derechos más básicos son ignorados o insuficientemente desarrollados en

* Me gustaría mostrar mi agradecimiento de corazón a las siguientes personas por sus perspicaces comentarios, sugerencias, y críticas en diferentes aspectos y fases de este trabajo: Primero y sobretodo a Joseph Weiler y a cada uno de los colegas del Inaugural Straus de 2009-2010, en la NYU School of Law. Philip Alston, Paolo G. Carozza, Grainne De Burca, Mary Ann Glendon, David Kretzmer, Jeremy Waldron, Massimo Luciani, Valerio Onida, Andrea Simoncini, Elisabetta Lamarque, Stefania Ninatti, Diletta Tega. Un agradecimiento especial a Alberto Llabrés, que ha realizado la traducción al español, con pasión, precisión y gran profesionalidad.

1 Esta expresión está tomada prestada del libro de MARY A. GLENDON, A World Made New, Random House, 1991, sobre el origen de la Declaración Universal de los Derechos Humanos, en referencia a las palabras de Eleanor Roosevelt. 
la práctica, e incluso manifiestamente conculcados. Dirigentes pertenecientes a regímenes represivos a menudo hablan y teorizan sobre el ideal de los derechos humanos mientras que en la práctica los ignoran. Para un gran número de seres humanos, la efectividad del consenso sobre los derechos humanos se ve lastrado por factores tales como la carencia de recursos o el bajo nivel de implementación de paradigmas democráticos que existe en muchos países.

Por otra parte, en las naciones occidentales las reafirmaciones de derechos se multiplican y prosperan: se han convertido en la vara con la que medimos el progreso humano ${ }^{2}$ y han contribuido a situar la persona humana en el centro de la vida política y social ${ }^{3}$. El proyecto de derechos ha sido apoyado por las instituciones públicas y por la sociedad civil — como lo demuestra la proliferación de ONGs - hasta un punto en el que se ha instalado un progresivo descontrol de los discursos sobre derechos.

La reclamación de derechos por un lado, y la sobreabundancia de derechos por otro, afectan a diferentes áreas del mundo.

Este trabajo pretende centrarse en el discurso de los derechos de los países occidentales, en los que ha sido proclamada una nueva era de los derechos humanos, bajo la influencia de instituciones internacionales, especialmente después del fin de la Guerra Fría; una era de expansión de actuaciones iniciadas bajo la bandera de los derechos humanos ${ }^{4}$. Para ser más precisos, en Norte América, especialmente en los Estados Unidos la «revolución de los derechos» empezó algunas décadas antes, retrotrayéndose a los años sesenta del siglo pasado. En Europa, el discurso dominante de los derechos ha «aterrizado» más recientemente, en las últimas décadas del siglo XX, para tornarse en penetrante en el nuevo siglo ${ }^{5}$.

2 NORBERTO BOBBIO, L'eta' dei diritti, Turín, Einaudi, 1990, p. 255, que describe los derechos individuales como un signo de esperanza para la humanidad, un signo de la clara tendencia de la evolución humana hacia «lo mejor». La misma opinión es expresada por L. HENKIN, The Age of Rights, Columbia University Press, 1990.

3 M. A. GLENDON, «Justice and Human Rights: Reflections on the Address of Pope Benedict to the UN», Eur. J. Int'l. L., 19, 2008, p. 925, que analiza el discurso que el Papa Benedicto XVI dirigió a la asamblea de la ONU el 18 de Abril de 2008.

4 Un repaso de la proliferación de derechos y algunos de los debates a propósito de los nuevos derechos se ofrece por CARL WELLMANN, en The Proliferation of Rights: Moral Progress or Empty Rehoric?, Westview Press, 1999.

5 El hecho de que Europa atraviesa por una «proliferación explosiva de derechos humanos o fundamentales tutelables judicialmente» es ampliamente constatado. Ver, p. ej. DANIEL KELEMEN, «The EU Rights Revolution: Adversarial Legalism and European Integration», en TANJA A. BORZEL \& RACHEL A. CICHOWSKI (eds.), The State of the European Union: Law, Politics and Society, 2003, págs. 221-234. 
Hoy todo el occidente se ha convertido en la tierra de los derechos, donde los derechos individuales se encuentran en el vértice del éxito.

En un análisis más atento, sin embargo, no se puede evitar la percepción de un creciente sentimiento de malestar. Sin duda, los derechos humanos han alcanzado un inesperado grado de éxito y las instituciones de derechos humanos prosperan. No obstante, se pueden detectar algunos motivos de preocupación en relación con los derechos humanos en los corros de políticos, entre estudiosos y académicos, activistas de los derechos humanos y el común de las gentes, por muchas y variadas razones. En los países occidentales, los derechos están en una encrucijada entre el éxito y la preocupación: Una creciente atracción hacia los derechos humanos corre pareja con una sensación cada vez mayor de desasosiego ${ }^{6}$. En cierto sentido, los derechos corren el riesgo de convertirse en víctimas de su propio éxito. De hecho, el mismo éxito de los regimenes de derechos alienta que nuevas quejas o agravios se encuadren para ser tratados como materia de derechos humanos, hasta el punto de que en el mundo de hoy día, los derechos humanos se están convirtiendo en una idea política dominante. Pero cuantos más derechos humanos proliferan, más proliferan las voces de escepticismo.

Hace ya más de veinticinco años que surgieron las primeras advertencias acerca de que la proliferación de derechos podría amenazar la credibilidad y el merecimiento de reconocimiento de la tradición de los derechos humanos ${ }^{7}$. Si se abusa de la categoría de los derechos humanos, su mordiente legal puede disminuir y su fuerza verse empobrecida. La inflación de derechos produce su devaluación. Más aun, añadir nuevos derechos puede dañar el equilibrio global del conjunto de valores implicados en el proyecto de los derechos humanos. Cuanto mayor sea el número de derechos reconocidos, más probable será que resulten contradictorios entre sí $i^{8}$. La adopción de nuevos derechos tiene un precio: cualquier expansión será a costa de los derechos humanos tradicionales, e incluso a costa del proyecto de derechos humanos como tal. Es por el bien del propio proyecto de los derechos humanos por lo que incluso defensores acérrimos e indiscutidos de los derechos humanos a veces defienden que la retórica de los derechos debería ser suavizada. Con todo, hasta el momento tales advertencias no han sido tomadas en serio.

${ }^{6}$ CHARLES R. BEITZ, The Idea of Human Rights, Oxford University Press, 2009, págs. 3-7.

7 PHILIP ALSTON, «Conjuring Up New Human Rights: A Proposal For Quality Control», AM. J. INT’L. L., 78, 1984, pág. 607.

${ }^{8}$ Esta posición es compartida ampliamente entre los constitucionalistas europeos. Una muestra de esta postura se encuentra en LORENZO ZUCCA, Constitutional Dilemmas: Conflicts of Fundamental Legal Rights in Europe and the USA, Oxford University Press 2007, p. xi. 
A diferencia de lo ocurrido en la cultura europea, durante décadas, varias advertencias críticas sobre los derechos humanos han animado el debate público en Estados Unidos, incluso entre activistas de los derechos humanos. Solo quiero referirme a alguna de ellas; el debate americano se caracteriza por tener muchas polaridades: comunitarianismo versus liberalismo, universalismo versus particularismo, juristocracia versus democracia, centralización versus federalismo, derechos naturales versus contractualismo, etc. ${ }^{9}$. Muchas de ellas se remontan al legado de muchas críticas clásicas de los derechos del Siglo XIX, tales como las de Burke, Bentham, Marx. Esto representa una parte del debate liberal que, en contraste con la cultura americana ${ }^{10}$, fue ampliamente obviado y subestimado en Europa ${ }^{11}$.

En los últimos años, algunas de dichas críticas se han abandonado, mientras que otras están ganando prominencia. En la preocupación contemporánea acerca de los derechos humanos hay mucho más que la simple re-edición de la redundante crítica americana hacia los derechos humanos. Después de todo, los debates sobre derechos ahora se producen en un contexto social muy diferente al que imperaba en los años cincuenta o sesenta. Para bien o para mal, la revolución de los derechos ya ha producido sus frutos: se mencionan y afean muchas desigualdades y discriminaciones, se ha fortalecido a un gran número de víctimas, se han desatado ataduras tradicionales, etc. El marco histórico ha cambiado profundamente: aunque han transcurrido solo unas pocas décadas, el contexto social ha evolucionado rápida y considerablemente. Partiendo de esta profunda diferencia de mentalidad es como muchos académicos formulan preguntas tan incómodas como estas: «¿Qué clase de personas humanas está moldeando el proyecto de los derechos humanos?» — «QQué clase de humanidad está implícita en el discurso de los derechos humanos?» — y, por afinar la cuestión— « ¿Es nuestra Sociedad más humana gracias al éxito de los derechos humanos?»

Escuchemos a algunos testigos.

En sus recientes lecciones acerca de la expresión de odio, Jeremy Waldron presenta el caso de que en una sociedad bien ordenada la gente necesita apoyarse en «disposiciones de seguridad» («provisions of assurance»), señalando que de-

9 Algunas notas sobre algunas de esas críticas pueden leerse en MARK TUSHNET, «An Essay on Rights», en Tex. L. Rev., 62, 1984, p. 1363; CASS R. SUNSTEIN, «Rights and their critics», Notre Dame L. Rev., 70, 1995, p. 727; DAVID KENNEDY, «The International Human Rights Movement: Part of the Problem?», Harv. Hum. Rts. J., 15, 2002, p. 101.

10 El debate se recoge y actualiza en JEREMY WALDRON (ed.) «Nonsense upon stilts» - Bentham, Burke and Marx on the Rights of Man (1987).

11 En Europa, la crítica de los derechos humanos es aún muy limitada, o más bien inexistente, como señala Grainne De Burca, «The Language of Rights and European Integration?» en GILLIAN MORE \& JO SHAW (eds.), New Legal Dynamics of the European Union (1995). 
ben poder estar seguros de que cuando dejan su casa por la mañana pueden razonablemente esperar que no van a ser discriminados o humillados o aterrorizados. Necesitan sentirse seguros de que van a poder disfrutar de los fundamentos de la justicia: respeto a la igualdad y a la dignidad. Pero —aquí viene la parte más relevante de su argumento para nuestros propósitos - «la Sociedad no se convierte en bien ordenada por arte de magia. El efecto disciplinario expreso de la Ley puede que sea necesario como ingrediente para el cambio del corazón por parte de los ciudadanos que una Sociedad bien ordenada presupone» ${ }^{12}$. Sin embargo, la seguridad difusa y general para todos los habitantes en relación con los elementos de justicia más básicos es una cuestión de bien público: «como la iluminación de las calles, es un bien público que redunda en beneficio de los individuos ... pero que a diferencia de la iluminación de las calles, que puede ser suministrada por una compañía de servicios centrales, el bien público de la seguridad depende y es consecuencia de lo que miles de ciudadanos ordinarios hacen tanto por separado como juntos» ${ }^{13}$. Por lo tanto, por una parte, Waldron insta una regulación y una limitación de uno de los más básicos y clásicos derechos de la tradición liberal, la libertad de expresión. Asume que cientos de años de libertad de expresión sin limitaciones ni condicionamientos han generado una «sociedad que está lejos de estar bien ordenada — más bien, ordenada ocultamente de manera enfermizaal menos en lo que concierne a los elementos básicos de justicia y dignidad ${ }^{14}$. El alto grado de protección otorgado a un derecho individual no ha generado per se una sociedad mejor ordenada - ni más acogedora. Por otra parte, el concepto de Waldron de una sociedad bien ordenada supone la contribución y responsabilidad activa y de corazón de todos y cada uno de los ciudadanos. Si los ciudadanos no cumplen su papel, el reto de mejorar la vida social queda fuera del alcance de la acción de gobierno ${ }^{15}$.

Mirando hacia el otro lado del mundo occidental, Joseph Weiler va más lejos. No solo es que los derechos humanos no generan por arte de magia sociedades más humanas, sino que en ocasiones tienen justo el efecto opuesto. Su análi-

12 JEREMY WALDRON, «Dignity and Defamation: The Visibility of Hate», Harv. Law Rev, 123, 2010, págs. 1597 y ss., en concreto en p. 1623.

13 JEREMY WALDRON, «Dignity and Defamation: The Visibility of Hate», ibid., p. 1630 .

14 JEREMY WALDRON, «Dignity and Defamation: The Visibility of Hate», ibid., p. 1646, donde hace mención a la lamentable era de la esclavitud, discriminación y segregación que ha marcado la historia Americana.

${ }^{15}$ La misma cuestión sobre una ciudadanía más responsable, considerada, atenta es el objeto de Jeremy Waldron en «The Image of God: Rights, Reason, and Order», en JOHN WITTE y FRANK S. ALEXANDER, Cambridge Companion to Christianity and Human Rights (en prensa). 
sis se centra en Europa, en donde la insistencia en derechos humanos no ha conducido a una sociedad más cálida y acogedora. La acusación de Weiler contra la Unión Europea es muy severa: las actuaciones de las Instituciones Europeas están corrompiendo los valores sobre los cuales fue fundado el proyecto europeo democracia, derechos humanos, estado de derecho, solidaridad y paz- y que incluso predisponen a la indiferencia ante dichos valores. Weiler enfatiza que aunque debe dejarse claro que «nuestro compromiso en pro de los derechos humanos protegidos constitucionalmente no debe presentar fisuras ... la cultura de los derechos humanos puede producir consecuencias no intencionadas en ese mismo ideal más profundo... que coloca al individuo en el centro y apela a la redefinición de las relaciones humanas».

Siguiendo a Weiler, el propósito de los derechos humanos ha sido siempre poner el individuo en el centro, pero desgraciadamente, el resultado es una sociedad de individuos egocéntricos. De acuerdo con su punto de vista, existen dos degradaciones culturales que los derechos humanos han producido en Europa. La primera, la cultura de los derechos humanos «exige muy poquito de todos nosotros que creemos en ellos... no es proclive a las virtudes y sensibilidad necesarias para que existan una comunidad real y la solidaridad». Segunda, «la cultura de los derechos, se quiera o no, mina de alguna manera la contra cultura de la responsabilidad y el deber». El resultado es el avance del «materialismo personal, del egocentrismo, del aburrimiento al estilo Sartre y narcisismo en una sociedad que genuina y laudablemente valora la libertad y los derechos humanos» ${ }^{16}$.

¿Por qué esa contradicción? ¿Por qué un proyecto que se basa genuinamente en el intento de promover y proteger a la persona humana produce ese resultado tan desolador? Los problemas parecen severos porque emergen en contextos, como Europa y EEUU, en donde el proyecto de derechos humanos ha tenido éxito. Esto convierte la crítica en su conjunto en más desorientadora, porque sugiere que el problema no proviene de una insuficiente aplicación del proyecto.

Desde la Segunda Guerra Mundial, nos hemos apoyado en los derechos bumanos para asegurar el progreso moral de la humanidad. En nuestros días los derechos están en el epicentro de la preocupación pública y están boyantes, al menos en las democracias liberales (sociales), gracias al legado de anteriores generaciones. ¿Pero qué ocurre con lo «humano»? ¿No será que, concentrados en los derechos, hemos puesto lo bumano entre paréntesis?

${ }^{16}$ J. H. H. WEILER, «Europe - Nous coalisons des Etats, nous n'unissons pas des homes», disponible en http://www.iilj.org/courses/documents/2009Colloquium.Session9.Weiler.pdf, págs. 31 y ss. 
La finalidad de este trabajo es indagar en la tensión que aparentemente afecta a los derechos humanos en los países occidentales, y al mismo tiempo preguntarse acerca de las causas culturales de la actual dualidad que los derechos humanos están atravesando. Puesto que el objeto del análisis se limitará a países occidentales, no se deducirá ninguna distinción entre derechos humanos internacionales, derechos fundamentales constitucionales, derechos derivados de normas de rango legal, derechos de creación jurisprudencial, o derechos derivados de otras fuentes de derecho. Aun cuando se supone que cada una de las anteriores categorías juegan un papel diferente y se supeditan a un régimen legal específico, para nuestros propósitos resultará más útil contemplarlos como derechos, en conjunto, en una mirada integradora.

De hecho, la pregunta subyacente fundamental que guiará nuestra investigación es: «¿De qué manera los nuevos derechos lesionan nuestra concepción de la persona humana?» Nos centraremos en el sujeto de derechos y en la imagen legal de la persona humana que se configura a través del lenguaje y el ejercicio de los derechos.

\section{EL SUJETO DE DERECHOS: EL «YO»Y EL «NOSOTROS».}

Una de las críticas más compartida sostiene que el discurso de los derechos humanos sufre de un «pecado original», el del individualismo. Comúnmente se asume que los derechos humanos se originan en el Siglo XVIII, con la filosofía liberal de Hobbes y Locke, y que en consecuencia reflejan - y al mismo tiempo promueven-una concepción de la persona humana individualista, egoísta y atomizada, separada y aislada del resto de sus congéneres. El estado natural es el entorno en el que los originarios derechos liberales a la vida, a la propiedad y a la libertad fueron concebidos, y por definición el estado natural es un lugar de desconfianza en el que los hombres no tienen lazos sociales y en el que solo están preocupados por sus propios intereses egoístas. Homo bomini lupus.

Esta línea crítica se remonta a Karl Marx, quien fue el primero en apuntar en Sobre la cuestión judia (On the Jewish Question), $1843^{17}$, que la imagen implícita del hombre de los derechos es la de una unidad aislada, un individuo separado por su propio contexto social retirado a su interior. En la perspectiva marxista, la crítica de los derechos liberales se funde con una más general que abarca la crítica del liberalismo. Con el tiempo esa postura ha sido rechazada, puesto que conduce a

${ }^{17}$ Una revisión de la crítica marxista a los derechos humanos y el texto de Karl Marx puede leerse en JEREMY WALDRON (ed.) 'Nonsense upon stilts', op. cit., supra nota 10, págs. 119 y ss. 
disolver al individuo dentro del grupo, dentro de la clase, dentro de la estructura social en la que se encuentra adscrito. En ese contexto la persona humana queda devaluada. Esta crítica de los derechos individuales, además, ha desembocado más de una vez en un ataque contra la democracia liberal como tal, con consecuencias devastadoras. El final de la Guerra Fría ha desvelado cuáles son los resultados aberrantes de una idea de sociedad no basada en el valor único de todos y cada uno de los seres humanos como tales. Lo cual a su vez proporciona una base firme para abandonar la línea crítica de la democracia liberal por cuanto que propende a una comprensión reductiva de la persona humana, considerada entonces como una unidad intercambiable de un grupo o como un elemento indistinguible de una corriente social, sin valor individual específico.

En un cierto sentido esta línea crítica se basa en una simplificación similar a la implícita en la cultura individualista que pretende criticar. En ambas se enfatiza un entendimiento parcial de la persona humana, la una centrándose solo en el individuo olvidando sus dimensiones relacionales, y la otra asumiendo una visión holística de la sociedad, en la cual a los componentes singulares no se les confiere ningún valor, excepto el de ser parte de un todo. Ambas visiones llevan a un callejón sin salida. Establecen una especie de dicotomía, oponiendo el valor único de cada «yo» contra las circunscripciones relacionales de cada persona humana entendida como «nosotros». Es la misma dicotomía recurrente en el tiempo bajo diferentes etiquetas y telares, por ejemplo la de las disputas entre libertarios y comunitarios ${ }^{18}$, en las que cada parte asevera verdades parciales y en último término promueven una concepción antropológica reduccionista incapaz de comprender la completa complejidad de las características de la condición humana, en la que individualidad y la dimensión relacional están entretejidas.

La conexión entre derechos humanos y la filosofía liberal de Locke y Hobbes se da por sentada en general, y de alguna forma es cierta. Locke y Hobbes han mostrado una gran influencia en las declaraciones americana y francesa de los derechos al final del siglo XVIII, y a su vez dichas declaraciones han sido el modelo de muchas cartas de derechos contemporáneas internacionales y constitucionales.

Pero en cambio, lo que se da por sentado indebidamente es la naturaleza de la vinculación entre cultura individualista y derechos humanos. La pregunta que se debería plantear es si la conexión entre derechos humanos e individualismo que se asume en la filosofía anglosajona, es contingente o esencial. Por decirlo de otro modo, uno preguntaría: ¿Debe considerarse que la idea de derechos subje-

18 En un mismo sentido, ver E. H. WOLGAST, The Grammar of Justice, Cornell University Press, 1987, págs. 25-26 y MICHAEL J. SANDEL, Liberalism and the Limits of Justice, Cambridge University Press, $2^{a}$. ed., 1998. 
tivos es la causa y el origen de la intensa mentalidad individualista de las sociedades occidentales modernas, o más bien se trata de que el lenguaje de los derechos es bastante susceptible —o quizás incluso particularmente propenso- de ajustarse al intenso individualismo que invade la sociedad moderna occidental? ¿Están los excesos del individualismo realmente presentes en el ADN de los derechos individuales?

Los tratados más comunes ${ }^{19}$ de la historia de los derechos individuales consideran que han brotado del individualismo filosófico de la Ilustración. Siguiendo ese apunte, existe una dependencia intrínseca de los derechos respecto al individualismo liberal, puesto que esos derechos se consideran como los primeros frutos de dicha filosofía. Un análisis más detenido de la historia de las ideas en la Filosofía y en el Derecho, sin embargo, muestra que la noción de los derechos humanos ha ido fraguándose poco a poco gracias a las contribuciones de muchas otras tradiciones a los largo de los siglos y que está lejos de haber sido inventada de repente por una sola mente, en un determinado año de la historia humana. Huellas de la idea de los derechos subjetivos pueden encontrarse mucho antes de la época de la Ilustración, remontándonos a la Baja Edad Media y al Renacimiento. Se ha comprobado de manera convincente que la idea de los derechos humanos precede a la filosofía liberal, habiéndose empleado bastante antes por ejemplo por Francisco de Vitoria y Bartolomé de las Casas ${ }^{20}$ que defendieron los derechos de los Indios a la plena propiedad de sus tierras y que se aprovecharon - y desarrollaron- del lenguaje de los derechos subjetivos insertados en documentos legales de la Edad Media. Desde un punto de vista histórico, el Siglo XII es la cuna de los derechos subjetivos: mucho antes que con Locke y Hobbes, es en las discusiones de los decretistas del Siglo XII, empezando por el Decretum de Graciano circa 1140, donde encontramos una primera preocupación por los derechos subjetivos $^{21}$. De hecho, uno de los conceptos centrales de las teorías políticas modernas occidentales comenzó su andadura, casi imperceptiblemente, en las oscuras glosas de los juristas medievales.

19 Para un tratado ilustrativo de la relación entre el discurso moderno de los derechos y las ideas de la Illustración vid. ALASDAIR MCINTYRE, After Virtue, Notre Dame University Press, 1981; MICHEL VILLEY, Les droits de l'homme, Presses Universitaire de France, 1983.

${ }^{20}$ MICHELINE R. ISHAY, The History of Human Rights: From Ancient Times to the Globalization Era, Univeristy of California Press, 2004; P. CAROZZA, «From Conquest to Constitutions: Retrieving a Latin American Tradition of the Idea of Human Rights», in Hum. Rts. Q., 25, 2003, pág. 281.

21 BRIAN TIERNEY, The Idea of Natural Rights, Scholar Press, 1997, págs. 54 y ss. 
Esta aclaración es consecuente no solo en aras de la precisión histórica, sino - más centrado en la cuestión — porque arroja una luz diferente sobre los precedentes culturales de los derechos humanos: si la idea es remontarse hasta la Baja Edad Media, eso implica que los derechos subjetivos no han sido necesariamente amamantados por una antropología individualista, no se basan en el egoísmo ni en meros intereses particulares; sino que más bien derivan de una visión de la persona humana individual como ser libre, dotado de razón, capaz de discernimiento moral, pero también perteneciente a grupos sociales, bien consciente de los múltiples lazos que ligan a unos individuos con los otros, y más en general de la dimensión relacional de la persona ${ }^{22}$.

Los derechos subjetivos no son propiedad intelectual de un pensador solo, tampoco fueron inventados por los filósofos liberales modernos. Los royalties, si los hubiera, deberían ser compartidos entre los muchos juristas desconocidos de la Edad Media, del Renacimiento y, por supuesto, de la Ilustración. Son múltiples las corrientes intelectuales y culturales que han concurrido para dar forma a la estructura de los derechos individuales.

El hecho de que la tradición liberal moderna haya supuesto una nueva etapa de los derechos humanos ${ }^{23}$ y que eventualmente haya dominado en su discurso legal y político no significa que la única posible construcción de los derechos sea aquella que se basa exclusivamente en un entendimiento del hombre como solitario y antagonista, preocupado de su supervivencia individual y seguridad en una tierra de lobos.

La Declaración Universal de los Derechos Humanos de 1948 es quizás la demostración más clara de que han sido intentadas y probadas otras alternativas en la historia. Una variada pluralidad de ideas filosóficas y antropológicas concurrieron en las discusiones y han quedado reflejadas en el texto final de la declaración Universal; entre esas ideas, la típica filosofía liberal moderna se atemperó y enriqueció gracias a la contribución de las antropologías Judía y Cristiana, a la insistencia sobre los derechos sociales y económicos aportada por los representantes de América Latina y países socialistas, y por la especial sensibilidad de las culturas orientales ${ }^{24}$.

22 Id., págs. 77 y ss.

${ }^{23}$ ERNEST L. FORTIN, Human Rights: Virtue and the Common Good, Rowman \& Littlefield, 1996, págs. 19 y ss. y 201 y ss.

${ }^{24}$ MARY A. GLENDON, A World Made New, op. cit., supra nota 1, que describe las interacciones entre los padres de la Declaración, y entre ellas las de Rene' Cassin, John P. Humphrey, Jacques Maritain, Charles Malik, Peng Chung Chan y sobre todo Eleonore Roosevelt, Presidente de la Comisión. 
No obstante, un documento escrito, por sí solo, no puede completar la tarea. El lenguaje de los derechos es con frecuencia laxo y abierto, de manera que dependiendo de las premisas antropológicas que se asumen en el discurso relativo a los derechos, los derechos humanos pueden ser moldeados de acuerdo con una comprensión rica y exhaustiva de la persona humana, o de acuerdo a otra empobrecida y por tanto distorsionada. Declinar los derechos humanos como una intensa y excesiva forma de individualismo ${ }^{25}$ es una de las tentaciones más extendidas de la sociedad occidental actual. La Historia demuestra que cuando los derechos humanos se anclan en una visión individualista de la condición humana, ponen de manifiesto algunas desventajas importantes que exigen ser tomadas en serio. No es ninguna sorpresa: los derechos humanos hablan de los seres humanos, por lo que cuando interactúan con una concepción reduccionista de la persona humana, representan y promueven una imagen empobrecida de la condición humana y están abocados a resultar en una sociedad de extraños y enemigos, una sociedad en la cual «ningún hombre conoce o se preocupa de quien es su vecino, a menos que su vecino provoque demasiadas molestias» ${ }^{26}$.

Siguiendo por este camino, la investigación necesita dirigirse hacia el sujeto de los derechos. ¿Quién es el «humano» de los derechos humanos en la práctica dominante contemporánea? ¿Cuáles son sus, de él o de ella, características cuando actúa como titular de sus derechos? ¿Cuáles son los efectos que la práctica contemporánea de los derechos humanos produce en la acepción de la persona humana, tanto como individuo como en su relación con los otros?

\section{3. ¿QUIÉN ES EL SUJETO DE LOS NUEVOS DERECHOS? CASOS DE PRIVACIDAD EN EL DERECHO NORTEAMERICANO}

Consideremos algunos de estos «nuevo derechos» originados a partir de la matriz del derecho a la privacidad (privacy), uno de los conceptos legales más prolíficos de nuestros tiempos. No constituye ninguna sorpresa el hecho de que muchos nuevos derechos hayan brotado de la privacidad: hay un aspecto atractivo en los derechos de privacidad, porque apuntan a la emancipación y liberación del individuo de todos los impedimentos legales y sociales, de manera que su libertad,

25 NICHOLAS WOLTERSTORFF, Justice, Princeton University Press 2008, pág. 388: «Un espíritu de individualismo posesivo distorsiona nuestras formas de trabajar con los derechos ... Un espíritu de individualismo posesivo emplea el lenguaje de los derechos para sus propios propósitos. Pero para determinar el origen de ese espíritu tenemos que buscar en otro lugar...».

26 T. S. ELIOT, The Choruses from the Rock, 1934. 
de él o ella, aparece altamente ensalzada. Es en estos nuevos derechos nacidos a la sombra de la privacidad en los que el individuo parece estar en su cenit. Es precisamente por ese alto valor atribuido a la autonomía individual por lo que el derecho a la privacidad comenzó a expandirse en los años sesenta y setenta del siglo pasado y hoy se ha convertido, de lejos, en el «triunfo» («As» de un juego de cartas, trump $)^{27}$ del debate actual acerca de los derechos humanos. A la luz de la privacidad, el individuo aparece liberado de todas las limitaciones y se le dota de facultades para ser el dueño y señor de su propia vida. Existe una estrecha conexión entre el alto valor que la privacidad otorga al individuo como dueño de su vida, y el hecho de que muchos «nuevos derechos» sean brotes de ella. Por esa razón, la privacidad está convirtiéndose en uno de los pase para todo (pass partout) de los nuevos derechos - el otro es el principio de no discriminación.

Mientras que en su origen los derechos de privacidad no eran más que una «expresión» libertaria, un dialecto dentro del discurso de los derechos humanos, actualmente se están convirtiendo rápidamente en la corriente principal del Esperanto legal ${ }^{28}$ de las sociedades occidentales. Los derechos de privacidad aparecieron por primera vez en la cultura legal americana ${ }^{29}$, y solo después de algunas décadas también se convirtieron en moneda de cambio en el sistema europeo. Después de su primer debut en casos de contracepción y aborto ${ }^{30}$, los derechos de privacidad florecen en el suelo fértil de las disputas bioéticas, en relación con los límites (comienzo y final) de la vida. En este terreno, una nueva y entera generación de derechos se está desarrollando como una consecuencia del valor de la privacidad individual. Tomemos en consideración primero algunos ejemplos de los precedentes jurisprudenciales (case law) de América, y posteriormente fijémonos en algunos ejemplos europeos para poder hacernos una idea del desarrollo de los derechos de privacidad en el mundo occidental.

Los casos pueden leerse bajo distintas perspectivas. Muy a menudo los casos se leen para discutir el método de interpretación, valorar la coherencia de la sentencia con el precedente jurisprudencial/legal, para revelar el punto de vista político de los jueces, o simplemente para criticar las consecuencias finales de la

27 La teoría de los derechos como «trumps» la desarrolla RONALD M. DWORKIN, «Rights as Trumps», en Jeremy Waldron (ed.), Theories of Rights, 1984, págs. 153 y ss., y RONALD M. DWORKIN, Taking Rights Seriously, Duckworth 1978, pág. 269.

28 Tomamos la expresión de J. KLABBERS, «Glorified Esperanto? Rethinking Human Rights», en Finnish Yearbook of International Law, 2002, págs. 63-77.

${ }^{29}$ La idea fue inventada por Samuel D. Warren y Louis D. Brandeis, «The Right to Privacy», Harv. L. Rev., 196, 1980 .

${ }^{30}$ Una retrospección histórica del derecho de privacidad se encuentra en MARY A. GLENDON, Rights Talk, Free Press, 1991, págs. 48 ss. 
resolución. Nuestro objetivo es muy específico: queremos familiarizarnos con el sujeto de los derechos. Así que, intentemos por un momento centrar nuestra atención en una cuestión un poco inusual: ¿Que tipo de ser humano está implícito en la manera de razonar del tribunal? ¿Se trata de un ser humano real (el o ella) que pueda ser encontrado por la calle? ¿Qué clase de humanidad ponen al descubierto los nuevos derechos?

Para nuestro experimento trataremos de comparar dos casos de la Corte Suprema de los EEUU, el primero que afirma un Nuevo Derecho al amparo de la privacidad y el segundo denegando las pretensiones del demandante, y ambos relativos a uno de los temas más candentemente debatidos tanto en Europa como en América: el término de la vida. Podríamos haber escogido cualesquiera otros casos de la jurisprudencia europea o de otros países occidentales ${ }^{31}$ sobre el mismo objeto: todos siguen la misma línea de razonamiento. Utilizaremos los casos americanos porque la imagen de persona humana está mejor delineada.

Los dos casos son Cruzan y Glucksberg, dos referencias legales del «derecho a morir» en EEUU. En Cruzan ${ }^{32}$ el Tribunal Supremo de EEUU dedujo a partir del derecho de privacidad el derecho del paciente a rehusar un tratamiento médico no deseado aun cuando le mantuviera con vida, habida cuenta de que la familia acreditó por medio de evidencias claras y convincentes que la persona habría querido que se retirase el tratamiento que le mantenía con vida. En Glucksberg $^{33}$ el Tribunal Supremo de EEUU decidió que la Constitución Americana no amparaba el derecho al suicidio asistido. Se ha trazado una línea legal clara entre suicidio asistido y retirada (rechazo) de un tratamiento de mantenimiento vital, prohibiendo el primero y permitiendo este último ${ }^{34}$. Dejando de lado todas las dificultades implícitas en el asunto referentes a la eutanasia y todas las distinciones entre eutanasia activa y eutanasia pasiva, pacientes en uso de sus facultades o no (competent), así como muchas otras cuestiones delicadas, tratemos de re-leer los dos casos a la luz antes mencionada.

En Cruzan, el problema legal principal para el Tribunal fue discernir cuál era la pura y verdadera voluntad del paciente. El caso se presentaba complicado por-

31 A nivel europeo ver STEDH de 29 de abril de 2002, Pretty v. UK, n. 2346/02, denegando el derecho al suicidio asistido al amparo de los arts. 8 y 14 de la Convención Europea; en Canadá el Tribunal Supremo (S. de 30 de septiembre de 1993, Rodriguez v. British Columbia), también denegaba el derecho al suicidio asistido, pero la cuestión se encuentra hoy día en discusión.

32 U.S. Supreme Court, Cruzan v. Director, Missouri department of Health, 497 U.S. 261 (1990).

33 U.S. Supreme Court, Washington v. Gluckberg, 521 U.S. 702 (1997).

34 U.S. Supreme Court, Dennis C. Vacco v. Tomothy E. Quill, 521 U.S. 793 (1997).

(C) UNED. Revista de Derecho Político 
que el paciente había perdido el uso de sus facultades. ¿Cómo estar seguros de que la voluntad del paciente era genuina? ¿Qué clase de evidencia debía aportar la familia al Tribunal? Considerando que la decisión a tomar habría de tener efectos irreversibles, ¿Qué nivel de evidencia o acreditación debía requerirse? El Tribunal decidió que para permitir la retirada del tratamiento de mantenimiento vital era exigible un nivel muy alto de evidencia y por esa razón la resolución fue muy criticada ${ }^{35}$. Lo que es más interesante para nuestros propósitos es que a juicio del Tribunal la decisión correcta dependía de la voluntad del/de la paciente. La voluntad libre de la persona es el único aspecto que interesaba al Tribunal. La dificultad del caso estribaba en realizar una valoración conjunta de las pruebas en relación con la verdadera voluntad de la persona. No hay dudas, sin embargo, en cuanto a que el eje sobre el que pivotaba del razonamiento del Tribunal era la libertad de elección del paciente, y en definitiva su voluntad.

La figura legal de la persona implicada en Glucksberg es diferente: el enfoque se dirigía hacia las circunstancias concretas de quien ostentaba los derechos. Mientras que en Cruzan la protagonista del caso es la autonomía personal del individuo, la voluntad pura y libre, en Glucksberg el Tribunal estaba preocupado además por la situación real del individuo. En Glucksberg el Tribunal tiene en cuenta algunos factores relacionales, personales, fácticos y sociales que no estaban presentes en Cruzan. Por ejemplo en Glucksberg la Corte resalta que a menudo la gente que solicita ser asistida en su suicidio presenta carencias en su salud y en su nivel de bienestar económico. Pueden ser vulnerables; pueden ser personas pobres, ancianas, discapacitadas. En consideración a todo ello, el Tribunal prosiguió aseverando que las personas desfavorecidas deben ser protegidas frente al riesgo de abusos o el de coerciones sutiles e indebidas influencias por parte de los doctores, el personal sanitario o incluso los parientes. La insidiosa indiferencia hacia los enfermos terminales u otras personas desfavorecidas, añadida a una mentalidad de ahorro, podría producir una presión social y moral indebida y empujar a los más vulnerables a adoptar decisiones no deseadas ${ }^{36}$. Las mismas razones se encuentran en la base de las Observaciones Concluyentes del Comité de Derechos Humanos de la ONU en relación con la eutanasia en Holanda ${ }^{37}$ : considerando el alto número de casos de eutanasia ocurridos en Holanda y el riesgo de abuso y

35 RONALD M. DWORKIN, «Assisted Suicide: What the Court Really Said», N.Y. Rev. Books, 44, 1997, págs. 40-44.

36 La práctica de la eutanasia en Holanda muestra un elevado porcentaje de casos en los que no existe una petición expresa por parte del paciente.

37 CCPR/CO/72/NET/ 27 de agosto de 2001, reiterado en CCPR/C/NLD/CO/4 25 de agosto de 2009. 
mala praxis de la eutanasia, el Comité ha expresado sus serias preocupaciones acerca de la presión que podría conducir a la gente a solicitar o aceptar la eutanasia, acerca de la insensibilización y conversión en rutina de una práctica que por definición debería referirse exclusivamente a casos extremos y acerca del riesgo de que personal médico pusiera fin a la vida de recién nacidos con minusvalías. El derecho de privacidad (o de autonomía de la voluntad —autodeterminación- en el lenguaje legal Europeo) es percibido desde una posible situación concreta en que puede estar incurso el que ostenta el derecho y, con base en ello, el Tribunal Supremo desestima la pretensión de establecer bajo el paraguas de la privacidad un nuevo derecho fundamental al suicidio asistido.

Los titulares de derechos en Cruzan y en Glucksberg son sujetos diferentes: un individuo abstracto en el primero, una persona real en el segundo. Se da una contraposición grande entre el protagonista de Cruzan y los de Glucksberg. En el primer caso la mujer/hombre de los derechos es contemplada solo en su capacidad de libre elección, sin tener en cuenta sus necesidades, deseos, molestias, preocupaciones: una autonomía sin gravámenes ni limitaciones ${ }^{38}$. Separada de toda relación. Es un sujeto hecho de pura voluntad, de algún modo un noble, aunque abstracto, prototipo de la especie humana: parafraseando a Descartes, «Yo quiero luego existo», es la figura del titular de los derechos reflejada en Cruzan. En el segundo, el cuadro se ha enriquecido: el hombre/mujer de los derechos es una persona histórica, real, concreta, que vive unas circunstancias personales y sociales determinadas, que puede estar recibiendo interferencias no deseadas de otras personas, un bomme situe', por tomar prestada una famosa expresión de George Burdeau.

A diferencia de Cruzan, Glucksberg tiene en cuenta el contexto de la situación y de la relación en que vive el individuo, el contexto de las circunstancias de hecho, afectos y relaciones que pueden estar jugando un papel tanto en la formación de su libre elección como en las consecuencias de la decisión que ha de ser adoptada. Leido con detenimiento, Glucksberg desafía la presunción básica de la misma idea de privacidad, por ejemplo que la privacidad ampara decisiones personales que no se ven afectadas por otros y que no afectan a otros ${ }^{39}$. De algu-

38 Ver MICHAEL J. SANDEL, Liberalism and the Limits of Justice, op. cit., supra nota 18, en págs. 178-183 para un debate útil acerca de las diferencias entre el proceso y resultados de la deliberación en un individuo sin cargas (pura elección preferencial), y en una persona caracterizada por sus connotaciones constitutivas, historia y circunstancias.

39 Aunque hablando de una aproximación liberal general al «derecho a morir» esta presunción es desafiada por G.U. RESCIGNO, «Dal diritto di rifiutare un determinato trattamento sanitario secondo l'art. 32, co 2., Cost al principio di autodeterminazione interno alla propria vita», en $D i$ ritto Pubblico, 2008, págs. 101 y ss. 
na manera Glucksberg sugiere que, para bien o para mal, la libre voluntad de un individuo se ve siempre afectada por condiciones de facto de la vida y por las interacciones personales con otros; más aun Glucksberg previene acerca del riesgo de la vulnerabilidad de ciertos sujetos —enfermos, ancianos, niños, minusválidos, pobres, etc. — la «libre voluntad» individual puede ser inducida artificialmente, incluso manipulada, y en consecuencia viciada.

Dos maneras distintas de entender la persona humana conducen a dos conclusiones diferentes.

Los derechos de privacidad resultan atractivos por el acento que ponen en la libre elección, que es ciertamente un componente importante de la libertad humana. La fuerza y el mérito de los derechos que cubre la privacidad residen en que pretenden proteger al individuo de toda forma de coerción proveniente de poderes públicos o privados. Su pretensión es dar fuerza y emancipar a cada individuo. Pero, después de estudiar algunos casos sobre privacidad nos vemos empujados a preguntar: «¿En qué punto la emancipación se convierte en abstracción?» Una cuestión que debería ser objeto de debate es si el titular de derechos es tratado como una persona real, o por el contrario como una imagen abstracta de un individuo etéreo, consistente en pura voluntad, que no vive en tierra alguna, sin ataduras ni cargas. Cada elección es resultado de un proceso que tiene lugar en contexto dado, hecho circunstancias personales, sociales, culturales, relacionales que consciente o inconscientemente juegan un papel en la formación de la voluntad. La cuestión es esencial pero sutil, debido a que un individuo abstracto — como se muestra en los ejemplos del Tribunal Supremo de EEUUtiene la apariencia de un sujeto independiente liberado de todo condicionamiento, pero de hecho puede ser una fácil presa de todo tipo de poder insidioso e indebido. Una dosis de idealismo se entreteje en la figura del individuo que se define meramente como una pura voluntad libre, completamente autosuficiente, autónomo y libre de condicionamientos. Esta tendencia de los derechos de privacidad a centrarse tan estrecha y exclusivamente en la libre voluntad exigirá una atenta consideración porque puede poner en peligro la misma promesa de liberación que esos derechos conllevan.

\section{4. ¿QUIÉN ES EL SUJETO DE LOS NUEVOS DERECHOS? CASOS DE PRIVACIDAD EN EL DERECHO EUROPEO}

Aunque es indiscutible que los derechos de privacidad tienen su origen en América, han aterrizado en Europa bajo la etiqueta de «derechos de autodeterminación» (derechos de la autonomía de las personas), brotando copiosamente 
del artículo 8 de la Convenio Europeo de Derechos Humanos. La privacidad y la autonomía personal son fuentes productivas que constantemente inspiran nuevos derechos con un distintivo marchamo libertario - y que cuentan en los debates bioéticos un suelo fértil para nuevos derechos también en Europa- La «tradición dignitaria» de los derechos humanos que acostumbraba a estar implícita en el Viejo continente se repliega rápidamente bajo la presión en favor de la corriente libertaria de los derechos de privacidad. La «Europa de los derechos» del nuevo milenio se desarrolla rápidamente bajo la influencia de la cultura judicial libertaria, en muchas ocasiones por la intervención de las instituciones internacionales. Uno a veces llega a preguntarse si el Viejo Continente ha superado incluso su carácter de tierra oriunda de las libertades individuales en el camino hacia la autonomía individual, la libre elección y los derechos de privacidad.

Repitamos nuestro experimento consistente en analizar la identidad de los sujetos de los derechos según se desprende de las resoluciones de la Corte Europea. Un caso relativo a fertilización asistida — ahora nos fijamos en el comienzo de la vida - recientemente dictado por el Tribunal Europeo de Derechos Humanos ofrece una ejemplo claro del progresivo cambio desde una tradición «dignitaria» hacia otra «libertaria» de los derechos que tiene lugar en Europa.

En S.H. y otros vs. Austria ${ }^{40}$, el Tribunal Europeo de Derechos Humanos fue requerido para decidir en un caso relativo a la Reproducción con Asistencia Médica. En concreto, el objeto se centraba sobre una disposición de la Ley de Austria que prohibía algunas técnicas de reproducción artificial que utilizaban óvulos y esperma de donantes. La legislación austríaca regulaba de manera estricta y prácticamente prohibía la fertilización heteróloga, y los demandantes alegaban que dichas restricciones vulneraban el derecho a la privacidad y el principio de no discriminación. Asumían que la decisión de una pareja de tener o no tener descendencia es una expresión del derecho de privacidad y que las limitaciones impuestas por la legislación nacional para la utilización de ciertos tipos de técnicas de fertilización artificial constituía una causa de discriminación entre parejas que padecían distintas clases de impedimentos para procrear. Según el planteamiento de los demandantes, el derecho de privacidad asociado al principio de no discriminación debía conducir a remover todas las barreras legales existentes contra las técnicas de reproducción asistida.

Las razones que sustentaban las restricciones — tal y como explicaban las instituciones austriacas, el Gobierno y el Tribunal Constitucional, compartidas por otros estados intervinientes como Alemania- se basaban en un entendimiento «dignitario» de los derechos humanos, en el cual los derechos y liberta-

40 TEDH, Resolución de 1 de abril de 2010, n. 57813/00, S. H. y otros vs. Austria. 
des individuales nunca son absolutos: cada derecho tiene sus propias limitaciones al objeto de garantizar los derechos de otros, así como otros intereses de carácter general necesarios para una sociedad bien ordenada. En nuestro caso, las limitaciones impuestas por la legislación austriaca pretendían proteger determinados valores públicos e intereses concurrentes con el deseo individual de tener descendencia.

En primer lugar y sobre todo la ley buscaba prevenir la creación de relaciones de parentesco no habituales, tales como que un niño tuviera más de una madre biológica, con el fin de proteger el derecho de cada niño a una identidad biológica propia. Por otro lado, la ley apuntaba también a prevenir la explotación de las mujeres y la comercialización de óvulos, esperma, embriones y úteros. Un objetivo más pretendido por la legislación nacional era el de evitar el riesgo de utilizar las técnicas artificiales de fertilización para reproducción selectiva o eugenésica. Por todas estas y otras razones la legislación austriaca —afín a algunas otras legislaciones nacionales en Europa- mantenía una aproximación cautelosa hacia la fertilización heteróloga, en especial cuando se recurría a la donación de óvulos y útero de alquiler. En la legislación austriaca el «deseo de descendencia» ("wish of a child") — por usar las palabras de la Corte Europea — era valorado y respaldado pero aun así no era considerado como un interés absoluto: era regulado como uno de tantos elementos que deben ser equilibrados entre sí.

En contra de lo anterior, animada por diferentes preocupaciones, la Corte Europea decidió que el derecho a la privacidad, al amparo del artículo 8 de la Convención Europea de Derechos Humanos —leído en conjunto con el artículo 14 que establece el principio de no discriminación - engloba «el derecho de una pareja a concebir un niño y hacer uso de la reproducción asistida médicamente para conseguir tal fin» y que en consecuencia las limitaciones austriacas a la utilización de procreación heteróloga vulneraban la Convención Europea y que no podían justificarse ni siquiera sobre la base del margen de apreciación que el sistema europeo tradicionalmente pudiera conceder a los estados miembros del Tratado. El razonamiento del Tribunal Europeo se centró en «el derecho a tener un bebé» de los padres y en la cuestión de la no discriminación, mientras que el resto de intereses y valores fueron obliterados: obedeciendo a una aproximación libertaria típica en los derechos humanos, la Corte concedió prevalencia solo a la libertad individual, restando relevancia al resto de bienes y valores en juego. Los argumentos de la Corte Europea parten del camino tradicional en el cual el primer paso es comprobar si una disposición nacional interfiere con un derecho protegido por el Tratado Europeo de Derechos Humanos, y los siguientes pasos discernir si tal interferencia se justifica en base a otros intereses generales necesarios en una sociedad democrática y sometidos al principio de proporcionalidad. En este caso, 
después del primer paso, la opinión mayoritaria cambió el razonamiento en pro del principio de no discriminación, omitiendo el habitual examen relativo a la justificación de las limitaciones a los derechos protegidos por el Tratado y las exigencias de proporcionalidad. El resultado es una resolución que sobresee toda dimensión relacional y contextual de la persona humana: no solo es que la libertad de elección de los padres ganara por la mano sino que quedaron relegados a un segundo plano cualquier otro derecho o interés potencialmente en juego.

En cierta manera hay algo a la vez trágico e irónico en esta resolución, porque al tiempo que se reconoce un nuevo derecho a tener un hijo - cuyo contenido es constitutivo de una relación, la más fundamental de entre todas las relaciones humanas - solo se considera a los progenitores, y no se tienen en cuenta las consecuencias que pueda sufrir eventualmente el hijo: uno de los polos de la relación es olvidada. Aun cuando se trata de una materia inequívocamente relacional se utiliza una aproximación individualista.

No caigamos en error: el asunto que fue presentado ante la Corte es un verdadero jeroglífico y no tiene una solución sencilla. Cualquier otra respuesta alternativa habría tenido sus correspondientes costes e inconvenientes. Sin embargo, por muy discutible que pudiera haber sido cualquier otra opción, los argumentos y la respuesta proporcionada por la Corte Europea ponen de manifiesto una excesiva simplificación de la cuestión. En la resolución el peso decisivo se sitúa en el derecho a tener un bebé, el énfasis se pone solo en los deseos y pretensiones de los progenitores, mientras que cualquier posible consecuencia que pueda repercutir en el hijo es simplemente ignorada, al igual que en lo que se refiere al resto de intereses comunes.

Esta resolución es un buen ejemplo de la evolución que se está produciendo en el derecho europeo de derechos humanos, en la que podemos identificar tres características primordiales. Primero, que a diferencia de hace algunas décadas, hoy no es inhabitual que «nuevos derechos» sean añadidos por la legislación o por los precedentes judiciales (case-law): el presente ejemplo da por supuesto la existencia de un «derecho a tener un hijo», que es en realidad una expansión del derecho de privacidad, algo imprevisible hace tan solo unos pocos años. Segundo, muchos de los nuevos derechos se sustentan en el artículo 8 - derecho de privacidad (a menudo leído en combinación con el artículo 14, no discriminación) de la Convención Europea de Derechos Humanos, por lo que en la mayoría de los casos los nuevos derechos promueven y alimentan una manera de entender la persona humana completamente definida desde su autonomía y capacidad de autodeterminación. Tercero, los nuevos derechos individualistas son un componente esencial de la uniforme cultura legal que invade el continente, cuya expansión está barriendo gradualmente la rica pluralidad de tradiciones jurídicas que per- 
tenecían a los distintos países europeos. La expansión de los nuevos derechos, el desarrollo de un retrato individualista libertario de la persona humana, y la centralización del entendimiento común de los derechos humanos, son los tres componentes que concurren en la marca europea de los derechos humanos.

\section{DE UN SUJETO EMPOBRECIDO A UNA ATROFIA DE LA RESPONSABILIDAD}

Pues bien, después de examinar algunos ejemplos tomados de la práctica jurídica de America y de Europa, podemos ahora retomar el asunto de nuestra investigación: ¿Cuál es la imagen legal del hombre y de la mujer de los nuevos derechos individuales en los países de occidente, a ambos lados del Atlántico? ¿Cuáles son sus características y de qué adolece?

Los ejemplos americanos acerca del derecho a morir muestran que los nuevos derechos individualistas corren el riesgo de desconectar al individuo de su contexto, minusvalorando las dimensiones reales y concretas de la condición humana, y su impacto en la autoconciencia humana. En el ejemplo europeo, ni el interés general ni las dimensiones relacionales de la vida humana son tenidas en cuenta adecuadamente, acometiendo la situación exclusivamente desde la libertad para realizar los propios deseos- en nuestro caso el encomiable deseo de una pareja de tener un hijo.

Desconectados y abstractos, los nuevos derechos libertarios individualistas ofrecen un retrato pobre del sujeto humano, una imagen en la que las dimensiones históricas, fácticas y relacionales se ocultan tras una pantalla.

Estas taras han permanecido dentro del derecho de privacidad desde sus orígenes. Pretendiendo definir una esfera privada inviolable, en la que la persona particular estuviera protegida, a salvo del alcance del gobierno, fuera del alcance de otra gente — el derecho a ser dejado en paz — los derechos de privacidad desarrollaron un paradigma absoluto de libertad, extraída de la idea de propiedad. El resultado es un conjunto de derechos que alimentan una cultura de individuos soberanos, personas solitarias, desentendidas de toda relación y de toda circunstancia constitutiva. Los derechos de privacidad reducen al individuo a una mera capacidad de libertad de elección -a mera libertad procedimental, utilizando la terminología de $\operatorname{Sen}^{41}$. Aunque esta sea seguramente una concepción

41 AMARTYA SEN, «Elements of a Theory of Human Rights», Philosophy and Public Affairs, 32, 2004, págs. 315-353, y Id., The Idea of Justice, The Belknap Press of Harvard University Press, 2009, págs. 286-290. 
importante de la libertad humana, es igualmente cierto que yerra a la hora de capturar la entera complejidad de la persona humana. Mirar a la persona humana a través de las lentes de los derechos de privacidad significa tomar una perspectiva parcial y en última instancia olvidar algunas características humanas importantes. No es fortuito que la expresión judicial a ultranza de la cultura del individualismo - la expansión del derecho de privacidad y sus derivados, los valores de autonomía, de separación y en última instancia, soledad- haya abierto un debate que está lejos de zanjarse.

No es sorprendente en verdad que la más influyente y controvertida consecuencia del derecho de privacidad - Roe $v$. Wade — haya propiciado un debate profundamente divisor y $\sin$ fin $^{42}$ en respuesta a determinadas consecuencias indeseables a nivel social que produce esta concepción de la condición humana. Si uno revisa con detenimiento el debate acerca de los derechos de privacidad de los años setenta y ochenta, emerge una seria razón de preocupación, una que debiera tomarse en consideración en el momento de agrandar el número y el objeto de los nuevos derechos de privacidad. No es solo que los derechos individuales lesionen nuestra concepción del ser humano, ofreciendo una imagen empobrecida del sujeto bumano, sino que también afectan a nuestra gestión humana (buman agency), a nuestro comportamiento social: al centrarse en el beneficiario (receptorrecipient), los derechos liberales descentran al (sujeto) agente (agent) ${ }^{43}$.

En su apasionada y vigorosa crítica al dialecto libertario individualista de los derechos humanos que inundó America en la segunda mitad del Siglo XX, Mary Ann Glendon ${ }^{44}$ ha demostrado de manera convincente de qué modo la insistencia en la privacidad y en la libertad individual es caldo de cultivo de una sociedad de gente solitaria, lava todo sentido de responsabilidad y rompe todos los tipos de lazos sociales que en los tiempos de la fundación de los EEUU se tenían por garantizados en la vida social. Todas las dimensiones relacionales de la persona humana se dejan de lado y se dispersan y con ello toda idea de responsabilidad no solamente del propio éxito, sino también del bien común.

Bastante sorprendentemente, pueden apreciarse algunos acentos similares entre algunos de los defensores pro-elección, que agudamente han criticado la re-

42 Vid. MARY A. GLENDON, Rights Talk, op. cit., supra nota 30, págs. 47-75, especialmente p. 58; ELIZABETH FOX-GENOVESE, Feminism Without Illusion, University of Carolina University Press 1991, pág. 83. Para una revisión de la crítica feminista a Roe v. Wade, ver CARL WELLMANN, The Proliferation of Rights: Moral Progress or Empty Rehoric?,op. cit., supra nota 4, págs. 85 y ss.

43 NICHOLAS WOLTERSTORFF, Justice, op. cit., supra nota 25, págs. 176-179.

44 Vid. MARY A. GLENDON, Rights Talk, op. cit. supra nota 30, págs. 47-144.

(C) UNED. Revista de Derecho Político 
tórica de los derechos de privacidad individuales porque no reflejan una concepción enteramente comprehensiva, especialmente desde el lado de la mujer. La ética del cuidado ${ }^{45}$, por ejemplo, es una línea feminista de crítica frente al lenguaje de los derechos humanos que dirige la atención sobre algunas dimensiones de la persona humana que son usualmente olvidadas en la mentalidad común de la justicia y de los derechos. El objetivo de la crítica es el egoísmo y el aislamiento promovido por el discurso de los derechos, que deriva en un mundo que está preocupado y obsesionado por crear y mantener fronteras entre las personas, un mundo incapaz de generar.

La capacidad generadora de la vida social ${ }^{46}$ es un aspecto de la personalidad humana que los derechos individuales liberales están condenados a dejar de lado. Esta es la consecuencia de un entendimiento empobrecido del ser humano que se encuentra en el origen de las preocupaciones acerca del mal uso o abuso del lenguaje de los derechos humanos, antes referido ${ }^{47}$. Los derechos instan a no perjudicar a los otros, pero no promueven un movimiento positivo hacia los demás: se quedan cortos en cuanto a promover la atención y el cuidado hacia los demás. Debido a esta inherente limitación, una estructura de derechos no tiene capacidad para constituir la vida social ${ }^{48}$. Presentan un defecto funcional importante para ser efectivos cuando los elementos constitutivos de las relaciones humanas se desmoronan. En cierto sentido los derechos están disponibles para ser reclamados en los casos de fallo o error humano y ciertamente se activan cuando las relaciones se rompen. Ayudan, pero no cuentan con fuerza para generar o regenerar una relación humana. Los derechos han sido y aun tienen una importante función que cumplir, aunque es limitada: proporcionan una especie de garantía o seguro de fondo frente a las deficiencias humanas. Sin embargo, los derechos no promueven la acción humana, y pudieran incluso deprimirla ${ }^{49}$.

Más de treinta años después, la crítica a los derechos de la ética de la asistencia es todavía un tópico. La 'revolución de los derechos' de la segunda mitad del siglo pasado ha agitado las instituciones sociales tradicionales — familia, comunidades locales, comunidades religiosas, etc. - para descargarlas de lo individual y exaltar su autonomía. En la sociedad post moderna del nuevo milenio, el con-

${ }^{45}$ CAROL GILligan, In a Different Voice, Harvard University Press, $2^{a}$ ed., 1993.

46 CAROL GILLIGAN, In a Different Voice, op. cit., pág. 174.

47 Supra, las referencias que se hacen en el apartado 2 de este trabajo y a los trabajos de Jeremy Waldron y Joseph H.H. Weiler.

48 JEREMY WALDRON, «When Justice Replaces Affection: the Need for Rights», en JEREMY WALDRON, Liberal Rights, Cambridge University Press, 1993, pág. 370.

${ }^{49}$ J. H. H. WEILER, «Europe - Nous coalisons des Etats, nous n'unissons pas des homes», op. cit., supra nota 16, pág. 34 . 
texto histórico parece muy diferente: las ligaduras ya han sido desatadas y muchas de las restricciones de facto han sido convertidas en potencialmente removibles $^{50}$. En este contexto, surge un conjunto nuevo de problemas, el problema de preservar la autonomía individual sin desestabilizar aun más la urdimbre social, sino más bien reconstruyendo conexiones sociales interrumpidas. Para este propósito, los derechos liberales no son suficientes.

En el contexto de las sociedades occidentales contemporáneas, las limitaciones en la manera de entender lo que es la persona humana y el actuar humano no deberían ser fácilmente descalificadas como si se tratara de un truco conservador o como una especie de nostálgica crítica de tipo «neo victoriana» de los derechos: el reconocimiento de las limitaciones de los derechos liberales es relevante para todo el mundo, independientemente de su orientación religiosa o política, especialmente en la era en la que la precaria posición de las instituciones políticas y judiciales tiende a expandir y multiplicar esos derechos. En algunos casos, la reivindicación de nuevos derechos individuales es necesaria para adaptarse a los nuevos retos de la libertad humana. En otros, sin embargo, los nuevos derechos son inapropiados o un recurso meramente retórico. En ocasiones, «los nuevos derechos» podrían producir un efecto negativo. Con el fin de desarrollar esta idea, vamos a focalizar nuestra atención en el siguiente caso concreto: el de los derechos de los niños.

\section{6. ¿QUIENES SON LOS NIÑOS DE LOS NUEVOS DERECHOS?}

Los derechos de la infancia ofrecen un buen ejemplo de las tendencias actuales en derechos humanos presentes en los países occidentales, porque han sido recientemente sazonadas con un toque de liberalismo, sin precedentes en este ámbito. Los niños no son cosa nueva en los derechos humanos. La protección de la infancia está enraizada en una larga tradición constitucional e internacional. Sin embargo, algunas variaciones de los derechos de los niños insisten en su libertad de elección, su autonomía y su independencia. Los «nuevos derechos de la

50 A este propósito baste hacer mención a la teorías de género, según las cuales incluso los datos biológicos se encuentran a merced de la voluntad: el sexo y las características cromosómicas se devalúan y se consideran variables dependientes respecto a las preferencias y la autonomía de la voluntad del individuo, por lo cual el género puede cambiarse incluso varias veces en el transcurso de una vida. Sobre todas estas teorías, véase J. BUTLER, Scambi di genere. Identità, sesso e desiderio, traducción italiana de R. Zuppet, Sansoni, Milano 2004. 
infancia» reflejan el mismo énfasis en la libertad y la autonomía que son típicos de la nueva generación de los derechos liberales de los adultos.

Esta nueva aproximación a los derechos de la infancia ha sido anunciada por la Convención de los derechos de los niños de la ONU aprobada en 1989, y desde entonces un ferviente debate ha animado la cuestión

La aprobación de la Declaración per se no ha sido objeto de controversia. Ha sido bien recibida como uno de los avances más relevantes en el ámbito de derechos humanos. Junto con la Convención acerca de la tortura es virtualmente una de las primeras convenciones universales de derechos humanos, suscritas por 194 estados; es una de las más ampliamente ratificadas en la historia y ha sido considerada como un punto de inflexión en la lucha para alcanzar una justicia para los niños. Sin que esto haya causado sorpresas, ha sido bienvenida con gran entusiasmo, debido a que se prefigura sobre una sensibilidad hacia la infancia ampliamente difundida y compartida. No existen dudas de que la infancia debe ser protegida como la más valiosa y clara expresión de la humanidad. Nadie tiene dudas de que existen serios problemas y de que es necesario y urgente afrontarlos y oponerse a las persistentes y vergonzosas prácticas de tráfico de menores y de explotación sexual, abuso de menores y violencia por parte de adultos, trabajo de los menores, niños soldados, así como otras muchas formas de abuso a las que los niños están expuestos, que están lejos de estar erradicadas ${ }^{51}$. Si hay algo que provoca un sentimiento universal de indignación, es el mal y la violencia cometida sobre los menores. No se puede negar que existe el daño que se inflige a inocentes, ni tampoco que es unánimemente reprochado. Por esa razón, mantener una distancia o, peor, criticar los derechos de la infancia suena antipático y rechazable. Una postura semejante contra los derechos de los niños podría ser mal entendida como una postura en contra, o indiferencia contra, los mismos niños, lo que puede explicar por qué la Convención sobre los Derechos de los Niños ha sido bien recibida con alegría como una potencial fuente de bienestar para la infancia. Es cierto que la Convención ha sido realmente una fuente que hasta ahora ha contribuido a dar una consideración primordial a los intereses de la infancia ${ }^{52}$, a luchar contra algunos abusos de menores vergonzosamente extendidos y a movilizar instituciones gubernamentales y no gubernamentales a fin de

51 Ver los datos aportados en BETH A. SIMMONS, Mobilizing for Human Rights, Cambridge University Press, 2009, págs. 310-311.

52 El interés superior del menor es algunas veces un concepto controvertido y puede usarse para imponer a los niños un punto de vista de los padres u otros intereses de los adultos, como se sostiene por J. EEKELAAR, Family Law and Personal Life, Oxford University Press, 2007, pág. 158. Vid. además, PHILIP ALSTON (ED.), The Best Interest of the Child: Reconciling Culture and Human Rights, 1994. 
comprometer recursos destinados a mejorar las condiciones de vida de los niños a lo largo y ancho del mundo ${ }^{53}$.

No obstante, la historia de la Convención no contiene solamente de éxitos; es curiosamente desigual. Después de un glorioso primer capítulo, siguió otro más problemático. A medida que ha ido pasando el tiempo, algunas de las partes de la Convención han puesto de manifiesto un sentimiento difuso de confusión ${ }^{54}$. Los EEUU no han ratificado todavía la Convención, y no parece probable que lo hagan a corto plazo, pareciendo como que mantuvieran segundas interpretaciones acerca de este instrumento internacional. Esto puede ser resultado de las discrepancias que afloran entre ciertas partes de la Convención y la corriente legal americana principal que aborda el trato de la infancia ${ }^{55}$. La actitud americana es simplemente uno de los signos más evidentes de las dudas que han emergido con el tiempo. Muchas de las reservas por parte de algunos de los estados signatarios constituyen una prueba más del cambio de actitud en relación con los derechos de la infancia, en particular en relación con algunos «nuevos derechos» de la infancia recogidos en la Convención.

Si se realiza una lectura detenida, la Convención revela dos «almas» ${ }^{56}$. Muchos de sus cincuenta y cuatro artículos reafirman y apoyan la tradicional postura de compromiso de la ONU para mejorar la vida de la infancia en el mundo. Además de reafirmar las necesidades fundamentales de la infancia — salud, nutrición, sustento fisiológico, educación, etc.- la Convención aborda cuestiones como el abuso de drogas, desatención de los menores, los menores en los conflictos armados, necesidades especiales de los menores discapacitados, el trabajo de menores y otras formas de explotación. La importancia de la familia y de las relaciones con los progenitores se reconoce como «el entorno natural para el crecimiento y bienestar de los menores ${ }^{57}$. Todo esto, y mucho más, son los in-

53 Sobre los efectos de la Convención en las concretas condiciones de vida de los niños, vid. BETH A. SIMMONS, Mobilizing for Human Rights, op. cit, supra note 51, pág. 318 y ss., donde aborda los problemas del trabajo de los niños, la inmunización y los niños soldados.

54 Una aguda crítica a la Convención se realiza por LYNNE M. KOHM, «Suffer the Little Children: How the United Nations Convention on the Rights of the Child Has Not Supported Children», 22 New Int'l. L. Rev, 22, 2009, pág. 57.

55 Children's Rights in America: U.N. Convention on the Rights of the Child Compared with United States Law, American Bar Association, 1990; BRUCE C. HAFEN Y JONATHAN O. HAFEN, «Abandoning Children to Their Autonomy: The United Nations Convention on The Rights of the Child», Harv. Int'l. L. J., 37, 1996, pág. 449.

56 Esta dicotomía se asume por PHILIP ALSTON Y JOHN TOBIN, Laying the Foundations for Children's Rights, Unicef 2005; DAVID B. THRONSON, «Kids Will Be Kids?» Obio St. L. J., 63, 2002, págs. 979 y ss.

57 Convención de los Derechos del Niño de la ONU, Preámbulo. 
gredientes de una tradición legal bien establecida que considera a los menores como una clase específica de personas, merecedoras de medidas adicionales de protección, en consideración a su vulnerabilidad y sensibilidad. Nombraremos a esta primera «la aproximación como protección especial» de los derechos de la infancia. En paralelo con lo expuesto, una segunda y concurrente perspectiva aparece añadida en algunas partes de la Convención, una aproximación que persigue conceder a los menores emancipación y autonomía, incluyendo derechos al estilo de los de los adultos, tales como libertad de expresión y religiosa, libertad de asociación y de reunión y por supuesto el derecho a la intimidad y a la privaci$\operatorname{dad}^{58}$. Nombraremos a esta segunda «la aproximación como derechos de autonomía». Esta concepción no tiene precedentes y por esa razón la Convención de la ONU sobre los Derechos de la Infancia ha sido entendida en primer lugar como un punto de inflexión, incluso como un cambio de paradigma ${ }^{59}$.

La típica «aproximación como protección especial» fue asumida en documentos internacionales anteriores tales como la Declaración sobre los Derechos de la Infancia de 1924, la Declaración Universal de los Derechos Humanos de 1948, la Declaración de los Derechos de la Infancia de 1959 y a nivel nacional por la mayoría de las constituciones nacionales del mundo. De acuerdo con esta aproximación, los menores se consideran integrados en el contexto de sus relaciones con sus progenitores y el énfasis se centra en sus necesidades especiales de protección y desarrollo. Estos documentos son coherentes y utilizan el lenguaje de los derechos a la vez que el de las responsabilidades: asumen que el fundamento para el florecimiento de la infancia es una sana relación con sus progenitores (u otros adultos) y por esa razón conceden gran relevancia a las responsabilidades de los adultos en relación con los menores. Las necesidades materiales tanto como las intelectuales, las necesidades afectivas y espirituales de los menores han sido desgranadas en esos documentos internacionales y constitucionales ${ }^{60}$ como el contenido de las responsabilidades más relevantes que han de ser ejercidas por los progenitores, los tutores y las instituciones sociales.

58 Convención de los Derechos del Niño de la ONU, Preámbulo, art. 13-16.

59 PHILIP ALSTON Y JOHN TOBIN, Laying the Foundations for Children's Rights, op. cit., supra note 56, págs. 7-8.

${ }_{60}$ Para una historia del desarrollo de la idea de los derechos de la infancia, ver PHILIP E. VEERMAN, The rights of the Child and the Changing Image of Childhood, Martinus Nijhoff Publisher, 1992. Para la revisión de varias Constituciones y todos los textos internacionales relevantes, en PHILIP ALSTON y JOHN TOBIN Laying the Foundations for Children's Rights op. cit., supra nota 56 , págs. 2 y ss. y 23 y ss. 
Además de esa evolución, la Convención de la ONU sobre los Derechos del Niño de 1989 pretende dar un paso adelante, garantizando a los menores todos los derechos tradicionales antes reconocidos así como una serie de nuevos derechos que carecen de precedentes. La Convención tiene un objetivo muy amplio y comprehensivo, que abarca todos los tipos más importantes de los intereses de los menores: necesidades básicas, necesidades de desarrollo, y autonomía ${ }^{61}$. Aborda todas esas clases de intereses, mediante una larga lista de derechos sociales, económicos, civiles y políticos, incluidos algunos derechos aspiracionales, tales como los de un estandar de vida adecuado y otros atípicos, como por ejemplo el derecho al ocio, al tiempo libre, a jugar, a disfrutar de actividades de recreo ${ }^{62}$. Dentro de una lista de derechos tan extensa, una nueva «aproximación como derechos de elección autónoma» introduce algunas tensiones entre las diferentes partes de la Convención.

La «aproximación como derechos de elección autónoma» se urde, por ejemplo en el artículo 13 de la Convención: «Los niños tendrán el derecho a la libertad de expresión; este derecho incluirá la libertad para indagar, para recibir e impartir información e ideas de todo tipo, sin acepción de fronteras, ya sea oralmente, por escrito o imprenta, en forma de arte, o a través de cualquier otro soporte de la elección del menor». La amplitud de la libertad de expresión acordada en favor de los menores parece difícilmente compatible con su característica vulnerabilidad, especialmente en el contexto social y tecnológico contemporáneo en el que un uso incontrolado de Internet puede exponer al menor a imágenes, video, y textos inapropiados, sin olvidar el riesgo relativo a la pornografía pedófila. Aunque puedan ser impuestas algunas restricciones a la libertad de información de los menores por ministerio de la Ley —el artículo 13 reconoce la necesidad de proteger ciertos intereses como la reputación de terceros, la seguridad nacional, el orden público, o la moral y la salud públicas - este artículo en conjunto reproduce el cuadro general de disposiciones acerca de la libertad de expresión que puede encontrarse en muchos documentos internacionales o constituciones nacionales que se dirigen a titulares adultos. Su literalidad deja poco margen a la

${ }^{61}$ J. EEKELAAR, The Emergence of Children's Rights, Oxford Journal of Legal Studies, 6, 1986, pág. 161, subraya que en contraste con el consenso general sobre los intereses básicos y de desarrollo - la satisfacción de lo necesario se traduce en sostener una vida saludable del niño, su bienestar psicológico y sus capacidades de desarrollo_- los derechos de autonomía son criticados.

${ }^{62}$ Convención de los Derechos del Niño de la ONU, art. 27 y art. 31. Para una panorámica de los derechos incluidos en la Convención, vid. T. HAMMARBERG, «The UN Convention of the Rights of the Child - and How to Make It Work», Hum. Rts. Q., 12, 1990, pág. 97, y STEPHEN J. TOOPE, «The Convention On The Rights of the Child: Implication for Canada», en MICHAEL FREEMAN (ed.) Children's Rights: A Comparative Perspective,1996, págs. 33 y ss. 
peculiar condición de la infancia, o a la necesidad de protección especial de su sensibilidad.

Otro ejemplo de la «aproximación como derechos de elección autónoma», y probablemente más ilustrativo, que recoge la Convención es el artículo 16 referido al derecho a la privacidad. El lenguaje en este caso es muy vago: «Ningún menor habrá de quedar sujeto a injerencia arbitraria o ilegítima en relación con su privacidad, familia, hogar o correspondencia, ni tampoco a ataques ilícitos a su honor o reputación. El menor tiene derecho a la protección de la Ley contra tales injerencias o ataques.» Surge la cuestión de si este derecho a la privacidad de los menores debe ser interpretado de acuerdo con los criterios que se aplican al derecho a la privacidad de los adultos. ¿Ha de considerarse incluida la plena libertad de elección en materias éticamente discutidas habitualmente relacionadas con los derechos de privacidad de los adultos? ¿Incluye el derecho a la privacidad de los menores el derecho al aborto, a la contracepción, reproducción asistida, a rechazar tratamiento médico, incluso tratamientos que salven la vida, el derecho a morir, etc.? Más aún, ¿frente a quiénes pueden ser reclamados o ejercitados dichos derechos? ¿Se conciben para proteger a los menores solo frente al Estado, o también son ejercitables frente a los progenitores? Después de todo, la relación de los padres con el menor forma también parte de su vida privada y familiar; de manera similar, los lazos de un menor con un progenitor, o con quien tenga su custodia, son parte de su vida privada y familiar que ha de ser protegida dentro de sus derechos de privacidad. Llevar la autonomía del menor demasiado lejos puede tener un efecto rebote.

A menudo ese paso desde «derechos de protección especial» a «derechos de autonomía» se presenta como un indiscutible progreso a favor del bienestar de los menores. Se dice con frecuencia que mientras que la aproximación proteccionista ya superada es paternalista, bajo la nueva aproximación los menores son reconocidos como individuos ${ }^{63}$ con su propia y única personalidad y dignidad. Algunas voces, sin embargo, ofrecen un punto de vista diferente $e^{64}$.

La principal razón por la cual la «aproximación como derechos de autonomía» de los menores no está respaldada universalmente deriva del contraste existente entre el hecho de su condición de dependencia y la idea de autonomía y elección individual entreverada en el discurso liberal de los derechos. Mientras que el énfasis en la autonomía persiga el reconocimiento de la personalidad in-

63 T. CAMPBELL, «The Rights of the Minor: As Person, As Child, As Juvenile As Future Adult», en PHILIP ALSTON, STEPHEN PARKER Y JOHN SEYMOUR (EDS.) CHILDREN, RIGHTS AND THE LAW, 1992, págs. 1 y ss.; M. FREEMAN, «Taking Children’s Rights More Seriously», en $I d$., págs. 52-71. 
dividual de cada menor y su dignidad, no se suscitan dudas ${ }^{65}$. Sin embargo, una idea de autonomía como la de los adultos parece inapropiada para los menores, porque se desentiende de sus peculiaridades ontológicas. Un giro drástico hacia la expresión de los derechos liberales produciría la pérdida de la realidad más profunda del ser menor. El callejón sin salida que afecta a los derechos liberales de los adultos y vela la estructura relacional de la persona humana, muestra sus dramáticas consecuencias en relación con la infancia. Los niños, aun más que los adultos, ilustran los dilemas de la libertad dentro de las relaciones, y de la independencia dentro de las conexiones. Los menores viven y florecen en el contexto de una relación sana con adultos. Extraídos de un contexto relacional no pueden desarrollarse, pueden a penas sobrevivir. Habida cuenta de que la vida de los menores está enredada en una malla de relaciones, es invocable una cierta cautela a la hora de señalar nuevos «derechos de autonomía» en su favor: paradójicamente, algunos de esos nuevos derechos de los menores podrían ser «derechos erróneos» ${ }^{66}$. La experiencia de criar niños enseña que la independencia, autonomía y libertad no son el resultado de una temprana separación, sino el fruto de una saludable relación con adultos ${ }^{67}$. Las conexiones con otros presuponen las precondiciones para, más que obstáculos, una autonomía e individualidad de los menores $^{68}$.

En una palabra, la retórica de los «derechos de autonomía de los menores» es terriblemente tentadora y probablemente ha jugado un papel importante concitando la atención sobre errores sociales graves, concienciando acerca de ellos y

${ }^{64}$ Vid, entre otros muchos, JOHN. E. COONS ET AL., «Puzzling Over Children's Rights», en BYU L. Rev., 1991, págs. 307y ss.; L. MARIE JOHM Y M. E. LAWRENCE, «Sex at Six: the Victimization of Innocence and Other Concerns Over Children's Rights», Brandeis J. Fam. L., 36,1998, págs. 361 y ss, en concreto pág. 369; B. BENNETT WOODHOUSE, «Child’s Ccustody in the Age of Children's Rights: the Search for a Just and Workable Standard», Fam. L. Q., 33, 1999, págs. 815 y ss.; Id., «From Property to Personhood: a Child Centered Perspective on Parents' Rights», Geo Journal of Fighting Poverty, 5, 1998, págs. 313 y ss.

${ }_{65} \mathrm{La}$ historia del Derecho muestra que los menores fueron tratados como si fueran una propiedad privada de los padres o de quienes ostentaban su guardia y custodia. Desde esa perspectiva histórica el énfasis en la individualidad irrepetible de cada niño resulta necesario.

66 E. H. WOLGAST, The Grammar of Justice, op. cit., supra nota 18, en págs. 28 y ss., considera que los derechos de los pacientes y los derechos de los menores son claros ejemplos de derechos erróneos.

${ }^{67}$ Incluso los defensores de los derechos de los menores reconocen la precondición de la relación para el desarrollo de ellos mismos y que la esencia de uno mismo se desarrolla relacionalmente. Id., págs. 1882-84.

${ }_{68}$ ONORA O’NEILL, «Children's Rights and Children Lives», Ethics, 98, 1988, págs.445 y 462.

(C) UNED. Revista de Derecho Político 
para instar la actuación institucional con el fin de afrontarlos. Como mecanismo para movilizar el interés y la atención políticos, la retórica de los derechos de los menores ha logrado un buen grado de éxito. Sin embargo si nos preguntamos si, y en qué proporción, los menores están mejor hoy día como resultado de la insistencia en los nuevos derechos de los menores, al final del día, sospechamos que la idea de basarse en su autonomía es frustrante porque no refleja la experiencia real de los menores, cuyas vidas están inexorablemente interligadas con otros adultos. Olvidar este aspecto de la vida de los menores significa olvidar la esencia de su propia humanidad.

\section{EN LA ENCRUCIJADA ENTRE JUSTICIA Y PODER: EN FAVOR DE UNA APROXIMACIÓN REALISTA A LOS DERECHOS HUMANOS.}

¿Quién es el humano de los nuevos derechos humanos?

Durante este viaje por las aristas de los «nuevos derechos» hemos encontrado diferentes titulares de derechos, nos hemos familiarizado con algunas de sus características y hemos percibido un elemento recurrente: en muchos casos se esbozan aspectos parciales, aunque importantes, de la condición humana al tiempo que se obvia el todo. Muchos de los derechos de privacidad se enfocan sobre la libertad de elección y la autonomía mientras que dejan veladas otras dimensiones de la experiencia de lo humano. El resultado es con frecuencia una imagen legal reductiva del sujeto humano, en la que los titulares de los derechos aparecen, en cierto modo, artificiales, desdibujados.

En este punto, la investigación nos incita a buscar las razones de estos desafortunados efectos colaterales de los nuevos derechos. Sugeriría que una ambigüedad endémica afecta a la práctica o ejercicio expansivo contemporáneo de los derechos humanos, una práctica que al mismo tiempo se ve impulsada por el anhelo sin fin de justicia, y expuesta a una degeneración utópica. La prueba más evidente del riesgo de ceder a nuevas formas de utopía ${ }^{69}$ viene dada por el carácter abstracto, lejano de la experiencia real de las personas, del sujeto de los nuevos derechos: «volo ergo sum», parece ser la definición más apropiada del derecho de los nuevos derechos. Pero ¿un sujeto humano se constituye de pura voluntad?

El gran equívoco de los derechos humanos es suponer que cuanta más insistencia se haga en los derechos, más cerca se estará de la justicia como destino. Los derechos privados de toda limitación y la multiplicación de los derechos son el

69 SAMUEL MOYN, The Last Utopia, Harvard University Press, Cambridge Massacchussetts, 2010 . 
fruto de este deslizamiento. Su absolutización y la multiplicación de los derechos son las dos caras de la misma moneda, subproductos del mismo movimiento hacia una justicia más «perfecta». Derechos absolutos e innumerables son en verdad víctimas de su propio éxito: dado que los derechos han sido herramientas eficaces frente a algunas grandes injusticias causadas por un poder incontrolado, se tiende a reproducirlos, con el fin de alcanzar una mejor justicia. Pero añadir más derechos simplemente no obra el milagro. Desgraciadamente, los derechos ilimitados en número y en contenido están expuestos a una degeneración utópica que desconecta los derechos de la condición humana. El resultado es que se comportan con rapidez y sin lindes, pero se alejan de su destino.

Existe una paradoja en la justicia humana, que se olvida fácilmente: summus jus, summa injuria. La vieja sabiduría de la tradición del Derecho Romano nos recuerda que cada acercamiento humano al ideal de justicia está condenado al fracaso si no tiene en cuenta las limitaciones de los medios humanos, como en Ulises de Dante.

En cuanto se refiere a los derechos absolutos, la clave ha sido señalada hace algunos años por Mary Ann Glendon: «La absolutización es una ilusión y raramente es inocua. Cuando afirmamos nuestros derechos a la vida, la libertad o la propiedad, estamos expresando la esperanza razonable de que tales cosas puedan ser más seguras por medio de la ley y la política. Cuando afirmamos esos derechos de una manera absoluta, sin embargo, estamos expresando deseos infinitos e imposibles - ser completamente libres, poseer las cosas totalmente, ser dueños de nuestro destino, y amos de nuestras almas. Hay una dimensión trágica (pathos) al igual que soberbia (bravado) en estos intentos de negar la fragilidad y la contingencia de la existencia humana, en la libertad personal, y la posesión de innombrables bienes [...] Así, por ejemplo, aquellos que refutan la legitimidad del uso obligatorio del cinturón en los automóviles o del casco en las motocicletas frecuentemente dicen: «Es mi cuerpo y tengo derecho a hacer lo que quiera con él». Sin embargo, la paradoja de la existencia humana es que «el independiente individualista, sin casco y libre en la carretera, se convierte en el más dependiente individuo en la sala de lesionados de médula espinal» ${ }^{70}$. Se trata de algo que la lógica no puede explicar, pero la experiencia humana sí: «un droit porte' trop loin devient une injustice» (Voltaire). (Un derecho llevado demasiado lejos deviene en injusticia).

Lo mismo puede repetirse acerca de la multiplicación de los derechos. La pretensión que subyace en la expansión de la esfera de los derechos es promover la justicia. Más derechos para más justicia. No obstante, por una serie de razones

${ }^{70}$ MARY A. GLENDON, Rights Talk, op. cit., supra nota 30, págs. 45-46. 
sospechamos que la justicia no es una cuestión de cantidad. En el campo de la justicia la idea de progreso por medio de la acumulación no funciona.

Hay algunos argumentos clásicos contra la multiplicación de derechos que puede ser útil recuperar, de entre los cuales el más relevante es que todos los nuevos derechos deben interactuar con el resto de los «viejos derechos», que a su vez pueden verse preteridos en la valoración que se efectúe para equilibrar los intereses concurrentes: si se insiste en exceso en el derecho a la privacidad, por ejemplo, la libertad de expresión puede socavarse. La edad de los nuevos derechos podría fácilmente transformarse en la edad del conflicto entre los derechos.

Más todavía, tal y como la historia ha demostrado, el incremento del número de derechos ha multiplicado también los pleitos legales y los conflictos interpersonales. Con el tiempo la actitud de las personas se hace más litigiosa en relación con sus interacciones personales, haciendo que las relaciones humanas resulten más confrontacionales. A un nivel institucional, los nuevos derechos saturan el sistema legal y atascan las cortes de justicia, de lo que resultan intolerables demoras hasta que recae una resolución judicial que restaura el derecho fundamental. Como la experiencia europea evidencia, una excesiva duración de los procedimientos judiciales puede convertirse en si misma en una violación de los derechos humanos ${ }^{71}$. Una justicia lenta es en muchos casos una justicia denegada. Hay algo irónico en el caso del Tribunal Europeo de Derechos Humanos que por una parte condena procedentemente a un estado miembro por la excesiva lentitud de los procesos y por la otra acumula alrededor de 120.000 reclamaciones pendientes de resolver ante $\mathrm{si}^{{ }^{72}}$.

Aun más, la proliferación resulta en una saturación de derechos que inevitablemente invita a las instituciones públicas a escoger, abriendo la puerta a un abuso institucional de los derechos ${ }^{73}$. Los recursos institucionales legales y financieros serán siempre escasos, de modo que prometer a la gente una lista sin fin de derechos es vender una ilusión: ciertos derechos se verán priorizados en re-

71 Un buen número de resoluciones del Tribunal Europeo de Derechos Humanos se basan en el artículo 6 de la Convención Europea de Derechos Humanos y conciernen a la excesiva duración de los procesos. Muchos estados miembros sufren este problema endémico, especialmente Italia. La ironía aquí es que el proceso ante el Tribunal Europeo de Derechos Humanos se demora más y más, a medida que el inmenso número de demandas presentadas ante el Tribunal se desboca.

72 En 2009 había 199.300 casos pendientes ante el Tribunal Europeo de Derechos Humanos y en 2010 ese número ha aumentado. Ver estadísticas disponibles en http://www.echr.coe.int/NR/rdonlyres/C28DF50A-BDB7-4DB7-867F-1A0B0512FC19/0/ Statistics2009.pdf

73 ANDRAS SAJO, «Abuse of Fundamental Rights or the Difficulties of Purosiveness», en ANDRAS SAJO (ed.), Abuse: the Dark Side of Fundamental Rights, 2006, págs. 29 y 49. 
lación con otros, y la generosidad de la lista de derechos suscita expectativas que son imposibles de satisfacer. Si los recursos se destinan preferentemente a seguridad, es porque inevitablemente se estarán minorando de los destinados a educación o a asistencia sanitaria o a la administración de justicia, solo por dar un ejemplo, y esto es cierto no solo para los derechos sociales o económicos, sino también para cualquier clase de derechos: todos los derechos tienen coste ${ }^{74}$.

Finalmente hay una razón más sustantiva por la que la multiplicación de derechos es una vía ilusoria, un trampantojo (trump l'oeil). Un derecho siempre enfoca a un individuo desde un ángulo determinado y se centra solo en algunos, aunque importantes, aspectos. El hombre/mujer de derechos se describe siempre como potencial víctima o potencial demandante. Por definición los derechos no pueden abarcar todas las filiaciones de la experiencia humana. Necesidades y deseos, relaciones y responsabilidades, virtudes y carencias, son todos ellos elementos abocados a situarse fuera del objeto que abordan los derechos. Hay un punto ciego ineludible en el retrato que los derechos hacen de la persona humana, tal y como se ha puesto de manifiesto en los casos sobre privacidad. Es más, de hecho, muchos de los nuevos derechos provienen de un proceso de fragmentación. En concreto, todos los derechos que se derivan del principio de no discriminación participan de este carácter. En Europa, por ejemplo, el gran énfasis en el principio de no discriminación ha generado un creciente número de derechos especiales, comenzando por los derechos de las mujeres, los derechos de personas LGTB (lesbianas, gays, transexuales y bisexuales), los derechos de Roma, los derechos de la tercera edad, los derechos de los trabajadores inmigrantes, los derechos de la infancia, etc. El resultado es una imagen dispersa de la persona humana, retratada sobre la base de una sola, aunque relevante, característica de su identidad. Multiplicar los derechos no sirve para el propósito de completar la imagen. Una multiplicación de partes no lleva al conjunto en su totalidad (todo-uno). Al final, la persona humana se ve atrapada en aspectos parciales de su experiencia vital y la complejidad conjunta de la personalidad humana queda soslayada. A largo plazo, esta estrategia se queda corta en su objetivo de engrandecer la libertad y puede que incluso se torne en formas de opresión diferentes y más insidiosas. Claramente, los nuevos derechos no tendrán la capacidad necesaria para sostener un desarrollo cabal e integral del potencial humano, si la imagen de la persona humana en la que se fundamentan es absurda y distorsionada.

${ }^{74}$ STEPHEN HOLMES \& CASS SUNSTEIN, The Cost of Rights, WW Norton, 1999. Un verdadero «Mercado de derechos humanos» está surgiendo y está siendo explorado, por ejemplo por UPENDRA BAXI, The future of human rights, Oxford University Press, 3. ed., 2008, págs. 216 y ss., 276 y ss. 
«Los derechos tienen su sitio, pero su sitio está limitado» ${ }^{75}$.

Para algunos, esta frase puede sonar trivial y a Perogrullo — una especie de obviedad sin consecuencias-. En la era de la proliferación de los derechos, sin embargo, no es un asunto trivial. Existe una especie de soberbia (bubris-bybris) reptando dentro de la ilimitada práctica de los derechos humanos que convierte esta proposición en la más relevante. Urge en favor de una aproximación atemperada a los derechos humanos, basada en la presunción de que mientras los derechos humanos pueden ser herramientas útiles que ayudan a revestir la injusticia y pueden facilitar $^{76}$ la mejora de las condiciones de vida de la gente, bajo ningún concepto pueden pretender lograr la justicia perfecta. En la búsqueda incansable y sin fin de la justicia, los derechos juegan un importante papel, pero necesariamente dejan fuera mucho. Mejor dicho, tienen que dejar fuera mucho.

En su reciente libro acerca de la Idea de la Justicia, Amartya Sen corrige la idea más popular de justicia de acuerdo a ciertas intuiciones de vital importancia. Sugiere que el ${ }^{77}$ anhelo humano por la justicia debería procurar una corrección indefinida de la injusticia más que una celosa búsqueda de la «justicia perfecta» definible en sus propios términos ${ }^{78}$. Remediar la injusticia no es sinónimo de obtener la justicia. La historia nos advierte que cualquier idea de justicia que no concede la debida consideración a los límites de las posibilidades humanas genera aún más graves injusticias. La venerable sabiduría de nuestra civilización nos recuerda que la justicia está siempre expuesta a la distorsión: fiat iustitia et pereat mundus, y ciertamente - comenta Amartya Sen- «Si el mundo pereciera no habría mucho que celebrar». De manera parecida, no hay nada que celebrar si «la multiplicación de las reglas que definen los derechos no ha reducido, sino de hecho ha aumentado los riesgos de violaciones» y «la denegación de derechos en nombre de los derechos se extiende ${ }^{79}$. En la época de los derechos en los países

75 E. H. WOLGAST, The Grammar of Justice, op. cit., supra nota 18, pág. 49.

76 JAN KLABBERS, «Glorified Esperanto? Rethinking Human Rights», en Finnish Yearbook of International Law, 2002, págs. 63-77, Id., «Doing the Right Thing? Foreign Tort Law and Human Rights» en C. SCOTT (ed.), Torture as Tort, Hart Publis, 2001, págs. 553, 564.

77 AMARTYA SEN, The Idea of Justice, op. cit. supra nota 41, p. IX.

78 Una aproximación similar puede estudiarse en E. H. WOLGAST, The Grammar of Justice, op. cit., supra nota 18, pág. 146. La misma preferencia por una idea de contrastar la injusticia más que lograr la justicia perfecta, con referencia concreta a los derechos se encuentra en ALAN M. DERSHOWITZ, Rights From Wrongs, Basic Books, 2004, págs. 81-96, 160.

79 GIANLUIGI PALOMBELLA, «The abuse of rights and the rule of law», en ANDRAS SAJO (ed.), Abuse: the Dark Side of Fundamental Rights; op. cit., supra nota 73, pág. 5. En la misma dirección Lester J. Mazor, «Too many, Too much, Too strong: is there a need for a doctrine of abuse of political civil rights», en Id., págs. 294-308, en p. 308 sugiriendo que también los derechos pueden ser fuente de abusos. 
occidentales, la proliferación de derechos y la exageración de su importancia parece ser la nueva y seductora expresión de la perdurable paradoja de la justicia humana.

Los derechos, las Cartas de Derechos y las instituciones tienen su sitio. Asumen un lugar importante porque, aunque podamos pasar toda la vida sin reivindicar un solo derecho, los disfrutamos cada día. Pero aun así, su lugar es limitado. Y esto no es para reducir el papel de los derechos, por el contrario, es para ensalzarlos y encumbrarlos hasta su valor máximo. En cierto modo, una aproximación equilibrada a los derechos humanos es una aproximación realista siempre consciente de que la justicia es un objetivo supremo que está siempre en el punto de mira pero que nunca se ha alcanzado. Por paradójico que pueda parecer, «sin una perspectiva ulterior, la justicia es imposible» ${ }^{80}$.

\section{Title}

Are «new rights» always the right answer?

\section{Summary}

1. Introduction: Total rights. 2. The subject of rights. The I and the We. 3. Who is the subject of new rights? Privacy cases in American law. 4. Who is the subject of new rights? Privacy cases in European law. 5. From an impoverished subject to a diminished agency in privacy rights. 6. Who are the children of new rights? 7. At the crossroads between justice and politics: for a tempered approach to human rights.

\section{Resumen}

Este trabajo pretende centrarse en el discurso de los derechos de los países occidentales, en los que ha sido proclamada una nueva era de los derechos humanos, bajo la influencia de instituciones internacionales, especialmente después del fin de la Guerra Fría; una era de expansión de actuaciones iniciadas bajo la bandera de los derechos humanos. Para ser más precisos, en Norte América, especialmente en los Estados Unidos la «revolución de los derechos» empezó algunas décadas antes, retrotrayéndose a los años sesenta del siglo pasado. En Europa, el discurso dominante de los derechos ha «aterrizado» más recientemente, en las últimas décadas del siglo XX, para tornarse en penetrante en el nuevo

${ }^{80}$ LUIGI GIUSSANI, The Religious Sense, McGill-Queen's University Press 1997, p. 110. 
siglo. Hoy todo el occidente se ha convertido en la tierra de los derechos, donde los derechos individuales se encuentran en el vértice del éxito. Sin duda, los derechos humanos han alcanzado un inesperado grado de éxito y las instituciones de derechos humanos prosperan. No obstante, se pueden detectar algunos motivos de preocupación en relación con los derechos humanos en los corros de políticos, entre estudiosos y académicos, activistas de los derechos humanos y el común de las gentes, por muchas y variadas razones. En los países occidentales, los derechos están en una encrucijada entre el éxito y la preocupación: Una creciente atracción hacia los derechos humanos corre pareja con una sensación cada vez mayor de desasosiego. En cierto sentido, los derechos corren el riesgo de convertirse en víctimas de su propio éxito. De hecho, el mismo éxito de los regímenes de derechos alienta que nuevas quejas o agravios se encuadren para ser tratados como materia de derechos humanos, hasta el punto de que en el mundo de hoy día, los derechos humanos se están convirtiendo en una idea política dominante. Pero cuantos más derechos humanos proliferan, más proliferan las voces de escepticismo. La finalidad de este trabajo es indagar en la tensión que aparentemente afecta a los derechos humanos en los países occidentales, y al mismo tiempo preguntarse acerca de las causas culturales de la actual dualidad que los derechos humanos están atravesando. Puesto que el objeto del análisis se limitará a países occidentales, no se deducirá ninguna distinción entre derechos humanos internacionales, derechos fundamentales constitucionales, derechos derivados de normas de rango legal, derechos de creación jurisprudencial, o derechos derivados de otras fuentes de derecho. Aun cuando se supone que cada una de las anteriores categorías juegan un papel diferente y se supeditan a un régimen legal específico, para nuestros propósitos resultará más útil contemplarlos como derechos, en conjunto, en una mirada integradora.

\begin{abstract}
This paper is intended to focus on the rights discourse in western countries, where a new human rights era has been heralded in, under the influence of international institutions, especially after the end of the Cold War - an era of expansion of activities undertaken under the flag of human rights. To be sure, in North America, especially in the United States the «rights revolution» began some decades in advance, dating back to the sixties of the past century. In Europe, a pervasive rights discourse has «landed» more recently. Undoubtedly, human
\end{abstract}


rights have met with an unexpected degree of success and human rights institutions are prospering. However, some reasons of concerns about human rights can be detected for many different reasons. In western countries, rights are at a crossroads between success and concern: a growing attraction towards human rights goes hand in hand with a growing discomfort. In some sense, rights are running the risk of becoming victims of their own success. In fact, the very success of rights regimes encourages the framing of new grievances as rights issues, so much so that in today's world, human rights are becoming a pervasive political idea. But the more human rights proliferate, the more voices of skepticism proliferate as well. The aim of this paper is to look into the tension that apparently affects human rights in western countries, while inquiring about the cultural causes of the present ambivalence that rights are going through. As a matter of fact, the underlying fundamental question that will lead our inquiry will be: «How do new rights impinge upon our understanding of the human person?» Our focus will be on the subject of rights and on the legal image of the human person that is being shaped by the language and the practice of rights. From this perspective, the substance of rights is more relevant than their formal features, and therefore the difference between different levels of protection of individual rights can be here overlooked.

\section{Palabras clave}

Nuevos derechos, derechos de privacidad, sujeto de derechos, derechos humanos.

\section{Key words}

New rights, privacy rights, subject of rights, human rights. 
